\title{
TIPOLOGÍAS DE POBREZA EN CALI: UN ANÁLISIS CON BASE EN EL SISBEN
}

TYPOLOGIES OF POVERTY IN CALI: AN ANALYSIS BASED ON THE SISBEN

TIPOLOGIAS DE POBREZA EM CALI: UMA ANÁLISE BASEADA NO SISBEN

María Isabel Caicedo-Hurtado; María Castillo-Valencia

Magíster en Economía Aplicada, Universidad del Valle. Asistente de investigación, Universidad del Valle. ORCiD: 0000-0001-5395-8966. E-mail: maria.caicedo.hurtado@correounivalle.edu.co, Colombia.

Doctora en Economía, Universidad Federal do Rio Grande do Sul, Porto Alegre, Brasil. Docente de Economía de la Facultad de Ciencias Sociales y Económicas, Universidad del Valle. ORCiD: 00000003-4228-3902. E-mail: maria.d.castillo@ correounivalle.edu.co, Colombia.

\section{DOI: https://doi.org/10.22267/rtend.202102.154}

\section{Resumen}

Este trabajo tiene como objetivo realizar un análisis comparativo de las condiciones de pobreza de la población encuestada por el Sistema de Identificación de Potenciales Beneficiarios de Programas Sociales (SISBEN) para en el año 2009 en relación con la población encuestada en el 2019. Para ello,

\footnotetext{
${ }^{1}$ Este artículo es producto de una investigación financiada por la Vicerrectoría de Investigaciones de la Universidad del Valle y se encuentra en el marco del programa “Inclusión productiva y social: programas y políticas para la promoción de una economía formal", código 60185, que conforma Colombia Científica-Alianza EFI, bajo el Contrato de Recuperación Contingente No. FP44842-220-2018. Agradecemos el apoyo recibido por Carlos Alberto Londoño y Héctor Fabio Rodríguez en el procesamiento de los datos del SISBEN y a Diego Rodríguez Mariaca por la elaboración de la primera versión de los mapas.
} 
se calculó el porcentaje de hogares por debajo de la línea de pobreza monetaria, pobreza extrema y el porcentaje de hogares condición de necesidades básicas insatisfechas. Con base en estos cálculos se clasificaron los hogares de acuerdo a sus tipologías y se obtuvo el porcentaje de los hogares en condición de integración social, pobreza reciente, carencias inerciales y pobreza crónica siguiendo la metodología de Kaztman $(1989,1997)$. Un primer hallazgo que reportan los datos, es que los hogares que ingresaron en el 2019 al SISBEN se encuentran en peores condiciones que los registrados en el 2009. Un segundo hallazgo indica que, aunque la población en condición de pobreza se encuentra localizada fundamentalmente en las zonas de oriente y ladera, coexisten formas heterogéneas de pobreza y de igualdad de oportunidades en un mismo territorio.

Palabras clave: línea de pobreza; metodología de Kaztman; Necesidades Básicas Insatisfechas; pobreza; pobreza monetaria; SISBEN.

JEL: B50; C80; I30; I32; J46; J64

\begin{abstract}
This paper aims to carry out a comparative analysis of the poverty conditions of the population surveyed by the System of Identification of Potential Beneficiaries of Social Programs (SISBEN) for the year 2009 in relation to the population surveyed in 2019. To this end, the percentage of households below the poverty line, extreme poverty, multidimensional poverty and the percentage of households in social integration, recent poverty, inertial deprivation and chronic poverty were calculated following Kaztman's Methodology $(1989,1997)$. A first finding to be reported is that households that entered 2019 are in worse condition than SISBEN-registered households in 2009. A second finding indicates that, although the population in poverty is mainly located in the eastern and hillside areas, heterogeneous forms of poverty and equal opportunities coexist in the same territory.
\end{abstract}

Keywords: poverty line; Kaztman methodology; Unmet Basic Needs; poverty; monetary poverty; SISBEN.

JEL: B50; C80; I30; I32; J46; J64 


\section{Resumo}

O objetivo deste trabalho é fazer uma análise comparativa das condições de pobreza da população SISBEN. Para isso, foram utilizados os dados do Sistema de Identificação de Potenciais Beneficiários de Programas Sociais (SISBEN) comparando as informações da população registrada em 2009 com os dados da população cadastrada no período 2019. Foram calculados o percentual de domicílios abaixo da linha de pobreza monetária, pobreza extrema, pobreza multidimensional e de domicílios em integração social, pobreza recente, privação inercial e pobreza crônica, seguindo a metodologia de Kaztman $(1989,1997)$. Os resultados mostram que os domicílios cadastrados no período de 2019 estão em condição pior do que aqueles registrados em 2009. Além disso, os resultados mostram que a população em situação de pobreza está localizada principalmente nas áreas de periferia, porém formas heterogêneas de pobreza e igualdade de oportunidades coexistem no mesmo território.

Palavras-chave: linha de pobreza; metodologia de Kaztman; necessidades básicas não atendidas; pobreza; pobreza monetária; SISBEN.

JEL: B50; C80; I30; I32; J46; J64

\section{Introducción}

El Valle del Cauca aparece entre los cinco departamentos con menos pobreza monetaria del país (Departamento Administrativo Nacional de Estadística [DANE], 2019)². Entre junio del 2018 y 2019, la pobreza se redujo en 0,7\% (del 21,15 al 20,4\%, respectivamente), indicando que hubo más hogares a los que su ingreso, por encima de $\$ 1.029 .732$ (para una familia de cuatro miembros), les permitió adquirir una canasta básica. Frente a la pobreza multidimensional, que va más allá de contar con recursos monetarios, definida como privaciones que enfrenta un hogar si no alcanza a cubrir del 33\% de los indicadores asociados a la educación del hogar, a las condiciones de la niñez y juventud, salud, trabajo, acceso a servicios públicos domiciliarios y a la vivienda, el departamento mostró una reducción del 10,5\% en el periodo 2010 al 2018.

\footnotetext{
${ }^{2}$ Las cifras de pobreza monetaria provienen de la Gran Encuesta Integrada de Hogares aplicada por el DANE con una representatividad estadística en las 23 ciudades y áreas metropolitanas, zonas rurales y total nacional.
} 
A nivel de ciudades capitales y sus áreas metropolitanas, Cali se encuentra en el grupo de las seis ciudades con menos incidencia de pobreza monetaria en el país, manteniendo casi estable el porcentaje de la población que tiene un ingreso per cápita del hogar por debajo de la línea de pobreza (un 15,7\% en el 2018 frente a 15,5\% en el 2017) y por debajo de la línea la pobreza extrema (del 3,5\% en 2017 al 3,4\% en 2018, (DANE, 2019)). Estas estadísticas podrían ser esperanzadoras para la región frente a las capitales de otros departamentos como el Chocó, Guajira y Cauca que registran tasas de pobreza muy por encima de la tasa nacional. Sin embargo, otra realidad muy diferente describe los datos del Sistema SISBEN frente a cómo se distribuye la pobreza en Cali. Usando la información que provee este sistema para la ciudad, este artículo pretende estimar las diferentes tipologías de pobreza, en función de la línea de pobreza monetaria y las Necesidades Básicas Insatisfechas de los hogares, de acuerdo con la metodología de Kaztman (1989, 1997). Discutiendo, como contribución, la situación de pobreza de la población que ingresó al sistema en dos periodos de tiempo distintos: 2009 y 2019 y usando su lugar de residencia para clasificar comunas y barrios con estas tipologías. Aprovechando la riqueza de los datos, se incluyó un análisis sobre las condiciones de pobreza de la población juvenil. Los resultados indican que la situación socioeconómica de los hogares sisbenizados empeoró en el 2019 con respecto al 2009. Es decir, la nueva población que se registró en el sistema, en el 2019, fue clasificada con menor puntaje frente a la del 2009 y comunas de ingresos altos y medios que en el 2009, no registraban población SISBEN, ahora, en este último periodo, empiezan a ser habitadas por familias en condición de pobreza.

Este artículo está dividido en siete partes. La primera corresponde a la introducción. En la segunda se hace un recuento sobre la evolución de la definición de pobreza. En la siguiente sección se describe la situación de pobreza de la ciudad. En la cuarta, la evolución y cambios experimentados del SISBEN como instrumento para identificar potenciales beneficiarios de la focalización del gasto social. La metodología aparece en la sección quinta. En la sexta se presentan y se discuten los resultados para, en la séptima concluir el artículo.

\section{Referentes teóricos: medición de la pobreza}

Estudiar y calcular la pobreza es una decisión teórica, metodológica y hermenéutica. Por un lado, están cientos de definiciones de pobreza y, por otro lado, están las metodologías de cómo aproximarse a ella. Dependiendo del enfoque y método elegido los resultados pueden ser diferentes para una misma 
población, afectando, de paso, la manera en que se evalúan las políticas y programas para su reducción. Lo que sí es cierto es que, en términos conceptuales se ha producido un avance frente a los enfoques tradicionales de la línea de pobreza y pobreza extrema, al tratar de incorporar en la definición, otras dimensiones que superan lo material y se enfocan en las capacidades. En los últimos años, la discusión sobre el tema ha permitido la aparición de nuevos conceptos que fueron desarrollados inicialmente por Sen $(1979,1983,1984,1987)$ y que reconocen la condición de pobreza como una forma de privación social. Estos conceptos ahora son alentados por el Programa de Naciones Unidas para el desarrollo (PNUD) y la iniciativa de Oxford sobre Pobreza y Desarrollo Humano.

En Colombia, la Misión para el Empalme de las Series de Empleo, Pobreza y Desigualdad 2001-2012 (DANE y Departamento Nacional de Planeación [DNP], 2012) define la metodología para la construcción y medición de la pobreza. Para calcular el Índice de Pobreza Multidimensional se usa la metodología propuesta por Angulo et al. (2011), las líneas de pobreza y pobreza extrema se calculan y actualizan con base en Herrera (2010) y el Índice de Necesidades Básicas Insatisfechas con base en la propuesta de la Comisión Económica para América Latina y el Caribe [CEPAL] y la Organización Iberoamericana de la Juventud (2004) para América Latina.

Para el desarrollo de estas metodologías, Feres y Mancero (2001) realizan un balance de los métodos para la medición de la pobreza. Parten del enfoque de Sen $(1979,1987)$-capability approach- en el que no sólo contar con recursos económicos o monetarios permiten superar la pobreza, sino que se centra en la capacidad como un medio que posibilita mayor libertad para elegir, lo que afecta positivamente el bienestar humano. También abordan otras definiciones que incorporan dimensiones, desde lo psicológico y social, para establecer cómo estos elementos inciden en el grado de pobreza de las personas (Spicker, 2009) y consideran las metodologías asociadas a la medición de la línea de pobreza monetaria (Schubert, 1995) y a los índices de pobreza multidimensional que satisfacen propiedades axiomáticas deseables (Alkire y Foster, 2009).

Por otra parte, existen otras perspectivas sociohistóricas que acentúan la historicidad del concepto de la pobreza y, por ende, la necesidad de comprenderla, siempre sujeta a contextos específicos, en los que los tratamientos y las prácticas se circunscriben. Por ejemplo, con fin de evitar visiones generalizantes, Kaztman (1997) propone distinguir las características de la pobreza y marginalidad 
actual frente a las de la década de los años cincuenta en los países Latinoamericanos. ${ }^{3}$ Así, entonces, para la década de 1950, la mayoría de la población se desplazó masivamente del campo a las ciudades, asentándose de manera precaria en la periferia de los centros urbanos, pero pese a su situación de pobreza y marginalidad, muchos migrantes experimentaron ese desplazamiento como un ascenso social por el furor asociado a la conquista de bienes de consumo más variados que los disponibles en el campo, así como el acceso a servicios de salud, educación y a otras actividades de esparcimiento. ${ }^{4}$

En este contexto, la población pobre y marginal del país, de la década de los cincuenta, también experimentó un proceso de movilidad social, marcada por la expansión de un mercado interno naciente, que posibilitó la cualificación, el empleo y en consecuencia el ascenso social de ciertos segmentos de la población. Pero el desplazamiento y la marginalidad de los años noventa en adelante, parece estar más marcada por otro tipo de características, algunas de ellas, ligadas al conflicto armado y al narcotráfico, que imposibilitan el ascenso social de una población juvenil de origen urbano con limitadas posibilidades de gozar ciertas mejoras en sus condiciones de vida. Las nuevas lógicas de expulsión de la economía global, han estrechado y encogido los mercados laborales, incrementando el crecimiento de los desempleados de largo plazo y los niveles de pobreza vía ingresos (Sassen, 2015). Sin embargo, más allá de los recursos monetarios, es importe enfatizar en la distribución de los recursos y en cómo la población accede a la oferta de bienes públicos que ofrece la sociedad y más precisamente, como lo afirma Mier y Terán et al. (2012) en "cómo se pueden ubicar a los individuos, colectivos sociales, barrios o zonas de una ciudad en la escala de distribución de bienes, recursos y servicios en que se localiza el territorio” (p. 122). En esta línea de análisis, interesa clasificar los hogares, pero también interesa conocer cómo esa clasificación determina la situación de los barrios y comunas donde habitan estos hogares, en relación a la pobreza y cómo eso determina su nivel de segregación. Entendido este concepto como la concentración de grupos en un solo lugar con

\footnotetext{
${ }^{3}$ Merrick (1997), plantea que América Latina fue la región más urbanizada de las regiones en vía de desarrollo, producto de la migración interna impulsada por las desigualdades en el campo y las inversiones realizadas en los centros urbanos que ofrecían expectativas en términos de mejoras en las condiciones de vida. Estas inversiones estaban asociadas a la política de sustitución de importaciones, que hacía parte de una estrategia de industrialización en la cual, la educación como elemento cualificado de la fuerza de trabajo jugó un papel fundamental en las posibilidades de ascenso social de la población migrante.

${ }^{4}$ En Vásquez y Arroyo (2008), se destaca el desarrollo educativo y cultural para Cali y el Valle del Cauca con la fundación del Conservatorio (1932), la Banda Departamental, la creación de la Fundación Orquesta Sinfónica del Valle del Cauca, la creación de Incolballet, la transformación de Bellas Artes y la organización en 1955 de la Escuela de Teatro con el apoyo de Enrique Buenaventura.
} 
características socioeconómicas similares. En este caso, hablamos de un proceso de concentración de los pobres en barrios y comunas de una ciudad.

\section{La situación de pobreza en la ciudad}

La concentración de pobres en las zonas de ladera y de Aguablanca en el oriente, han definido el espacio y han convertido a Cali en una ciudad segregada. Para mostrar su nivel de segregación y el nivel de aislamiento de los grupos en condición de pobreza y marginalidad, Vivas (2013) calcula un índice de exposición y un índice compuesto de proximidad espacial, para corroborar los altos niveles de aislamiento de la población entre grupos con características socioeconómicas disímiles. ${ }^{5}$ Estos cálculos sugieren que la ciudad de Cali presenta configuraciones residenciales con altos niveles de aislamiento que se refleja en la persistencia de los patrones de segregación. Pero esta tendencia reciente tiene origen en la configuración espacial de las comunas de las zonas marginales de la ciudad de Cali (Mosquera y Aprile-Gniset, 1984). Urrea (1997), por ejemplo, muestra que el mayor porcentaje de hogares en condición de pobreza e indigencia en la década de los 80 y 90 se localizan en estas zonas. Su explicación radica en la naturaleza del fenómeno de migración-segregación espacial de poblaciones procedentes de regiones también pobres que no alcanzan, en un determinado, periodo a integrarse en mejores condiciones de vida de la ciudad.

Pero la pobreza no afecta de manera homogénea a todos los grupos de edad. Aunque en América Latina se han mantenido altos niveles de pobreza e indigencia con una tendencia persistente a su crecimiento, la incidencia de la pobreza e indigencia urbana sobre la población juvenil es mayor (CEPAL y Organización Iberoamericana de la Juventud, 2004). De acuerdo Sen y Kliksberg (2007) en América Latina entre los años 1990 y 2000 el número de jóvenes pobres subió a 58 millones y el de jóvenes indigentes a 21.200.000. Los cálculos realizados con base en las encuestas de hogares muestran que en América Latina (17 países) las tasas de desempleo son mayores para la población juvenil entre 15 y 29 años lo que aumenta la vulnerabilidad de este grupo. Esta tendencia se mantiene en las estadísticas recientes del mercado laboral colombiano y es una constante en los boletines técnicos del DANE. Para el caso de Cali, los datos de la Gran Encuesta Integrada de Hogares muestran

\footnotetext{
${ }^{5}$ Los índices se calculan con base en los datos del Censo de población del año 1993 y 2005. El índice de aislamiento mide la probabilidad de que un individuo comparta una unidad espacial con otro de un grupo diferente, el cual mide la segregación de cada grupo en función de otro.
} 
que tal tendencia se repite a nivel de área metropolitana y a nivel comunas y el análisis de los datos de la Encuesta de Empleo y Calidad de Vida para esta población muestra, también, una situación dramática para los que habitan las comunas de oriente y ladera, quienes enfrentan las tasas de desempleo e informalidad más altas. Las bases de datos del Sistema de Identificación de Potenciales Beneficiarios de Servicios Sociales (SISBEN) revelan que estas tendencias se mantienen para el caso de la ciudad de Cali.

\section{EI SISBEN como método para detectar pobres}

El SISBEN se implementó en 1994 como un sistema, a través de la aplicación de una encuesta, para la caracterización y ordenamiento socioeconómico de aquellos grupos de población vulnerables (Castañeda, 2005; Sarmiento et al., 1999; Vélez et al., 1999), que usa una escala de 0 a 100 para calificar a sus beneficiarios en términos de bienestar, siendo 100 el puntaje para quien se encuentre en mejores condiciones y 50 se considera equivalente a estar en situación de pobreza (ver Figura 1). Por ahora, el cálculo de puntaje de la población registrada bajo la metodología del SISBEN, indica que entre menor sea el puntaje de los hogares mayor es el número de privaciones y, de acuerdo con ese puntaje, se definen los beneficios a los cuales pueden tener acceso las familias. En 1997 esta herramienta se consolidó como un instrumento de identificación de los hogares y los individuos, en condición de vulnerabilidad, para aplicar a los beneficios de los programas sociales estatales relacionados con la salud, educación, vejez, vivienda e ingresos (DNP, 2012).

En el 2001 el Departamento Nacional de Planeación realizó una reestructuración del SISBEN para mejorar la capacidad de focalización individual a través de la implementación de un nuevo software y el rediseño de la encuesta. Nuevos mecanismos y marcos regulatorios fueron incorporados para una mayor calidad del dato y estandarización de procesos y procedimientos, reduciendo los errores de inclusión y duplicidad de registros. Con la Ley 715 de 2001, en el artículo 94, se reestructuró el sistema y se estipuló un Nuevo Sistema de Focalización del Gasto Social que exigía a las entidades territoriales la aplicación de los criterios de focalización para la distribución de subsidios estatales. Esta nueva ley dio el espacio a la creación de un instrumento SISBEN que se desarrolló con base en algunas variables y ponderadores con base en la información de la Encuesta de Calidad de Vida de 1997 y que fue implementado en el 2002. 
Sin embargo, debido a los cambios en la condición de vida de la población, el uso excesivo de algunas variables que determinan la pobreza de las personas y los problemas de manipulación en la información, surgió la necesidad de revisar y transformar nuevamente el instrumento. La implementación del nuevo SISBEN arrancó en el año 2011, orientado hacia un enfoque multidimensional de pobreza en el que se incluyó la salud, educación y vivienda, junto a otras variables asociadas a la vulnerabilidad individual y de contexto, como factores que afectan el bienestar de las personas y que permiten una mejor asignación de recursos de 18 programas sociales en función de los puntajes asignados (Figura 1). En esta figura se describen los diferentes beneficios ofrecidos por las dependencias del estado y el puntaje requerido.

\section{Figura 1}

\section{Programas sociales de acuerdo al puntaje SISBEN}

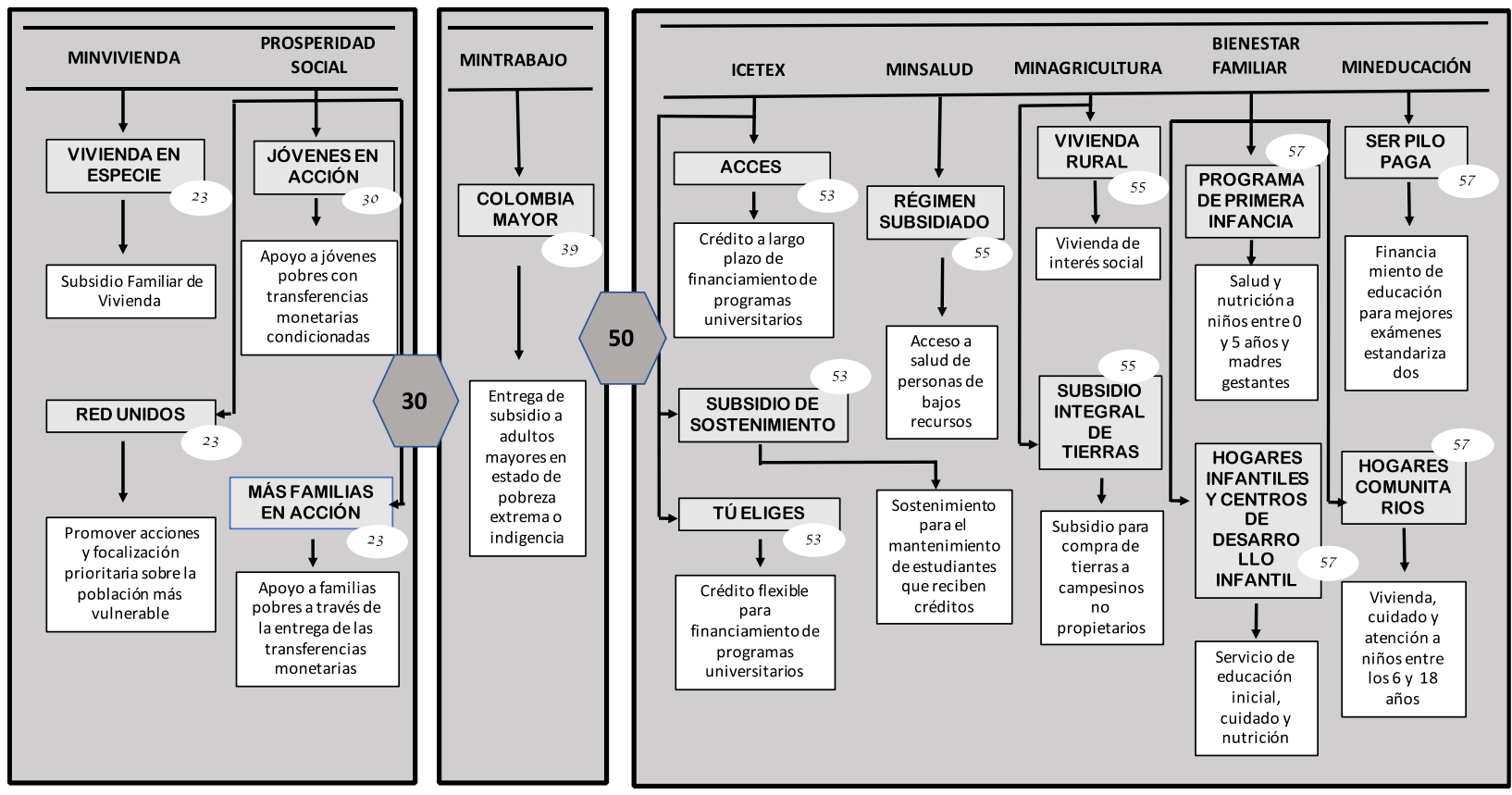

Fuente: tomado de López, 2020.

A pesar de los cambios experimentados por el instrumento, este sigue en constante monitoreo y evaluación debido a su importancia como único mecanismo para la asignación focalizada de recursos de inversión social. 
En el 2016 el SISBEN alcanzó una cobertura del 98\% de los municipios colombianos, contando con la información socioeconómica de 6.200.000 personas en las zonas urbanas y 6.500.000 en las rurales (DNP, 2016). Sin embargo, desde diferentes sectores se hacen críticas al instrumento como medidor de la pobreza del país. En el 2018 los concejales de Cali cuestionaron la encuesta al considerar que ese mecanismo no reflejaba la verdadera situación de pobreza de la ciudad y pedían al DNP modificar el instrumento (Concejo Santiago de Cali, 2018). En esa misma dirección, López (2020) crítica el algoritmo del SISBEN y lo considera como una caja negra:

“Tanto el algoritmo como el tratamiento de los datos del SISBEN son desconocidos por la ciudadanía que es clasificada. Por esto, hicimos una solicitud de acceso a la información al DNP pidiendo mayor claridad sobre los estudios previos que sustentan las variables elegidas para el algoritmo del SISBEN, las unidades de medida y especificidad de las variables tenidas en cuenta para predecir "la capacidad de generación de ingreso" (Departamento Nacional de Planeación-DNP, 2019). Sin embargo, la respuesta del DNP fue que "la información se encuentra sujeta a reserva", pues revelarla puede comprometer "la estabilidad macroeconómica y financiera del país" ya que "puede conllevar a modificar la información registrada en la base de datos constituyendo un fraude" (Departamento Nacional de Planeación-DNP, 2019, p. 4). Mientras el Estado utiliza los datos de las personas para otros objetivos y, a su vez, hace más transparente la vida de las personas, la ciudadanía conoce menos la forma en que la califican y los mecanismos con los que funciona el sistema”. (López, 2020, p. 13)

Frente a los problemas y críticas presentadas a la versión anterior, se propuso un nuevo SISBEN con el objetivo de ampliar sus bases de datos, recogiendo información adicional sobre los que ya se encuentran registrados en el sistema (Correa, 2017; López, 2020).

\section{Distribución de la población SISBEN para Cali}

La población SISBEN en Cali, actualizada a junio de 2019, alcanzó una cobertura del 60,2\% del total de la población. ${ }^{6}$ De 1.340.759 personas que fueron encuestadas, el 96,4\% se encuentra en la zona

\footnotetext{
${ }^{6}$ Este porcentaje se calculó con base en los datos del último censo de población DANE (2019), en el cual se reporta que la ciudad de Cali tiene 2.227.642.
} 
urbana y el 3,6\% en la zona rural. Estas personas conforman 442.440 hogares y habitan en su gran mayoría en las zonas de oriente (comunas 13, 14, 15, 16 y 21) y la ladera de la ciudad (Comunas 1, 18 y 20) que son las zonas de la ciudad de bajo estrato socioeconómico (Figura 2). De hecho, el 15\% del total de la población registrada en el SISBEN se encuentra localizada en la ladera y el $50 \%$ en el oriente, principalmente en las comunas 13 y 14 . Solo en estas dos comunas se concentran el $25 \%$ del total de la población de la zona urbana registrada en este sistema.

\section{Figura 2}

Mapas con la localización de la población SISBEN

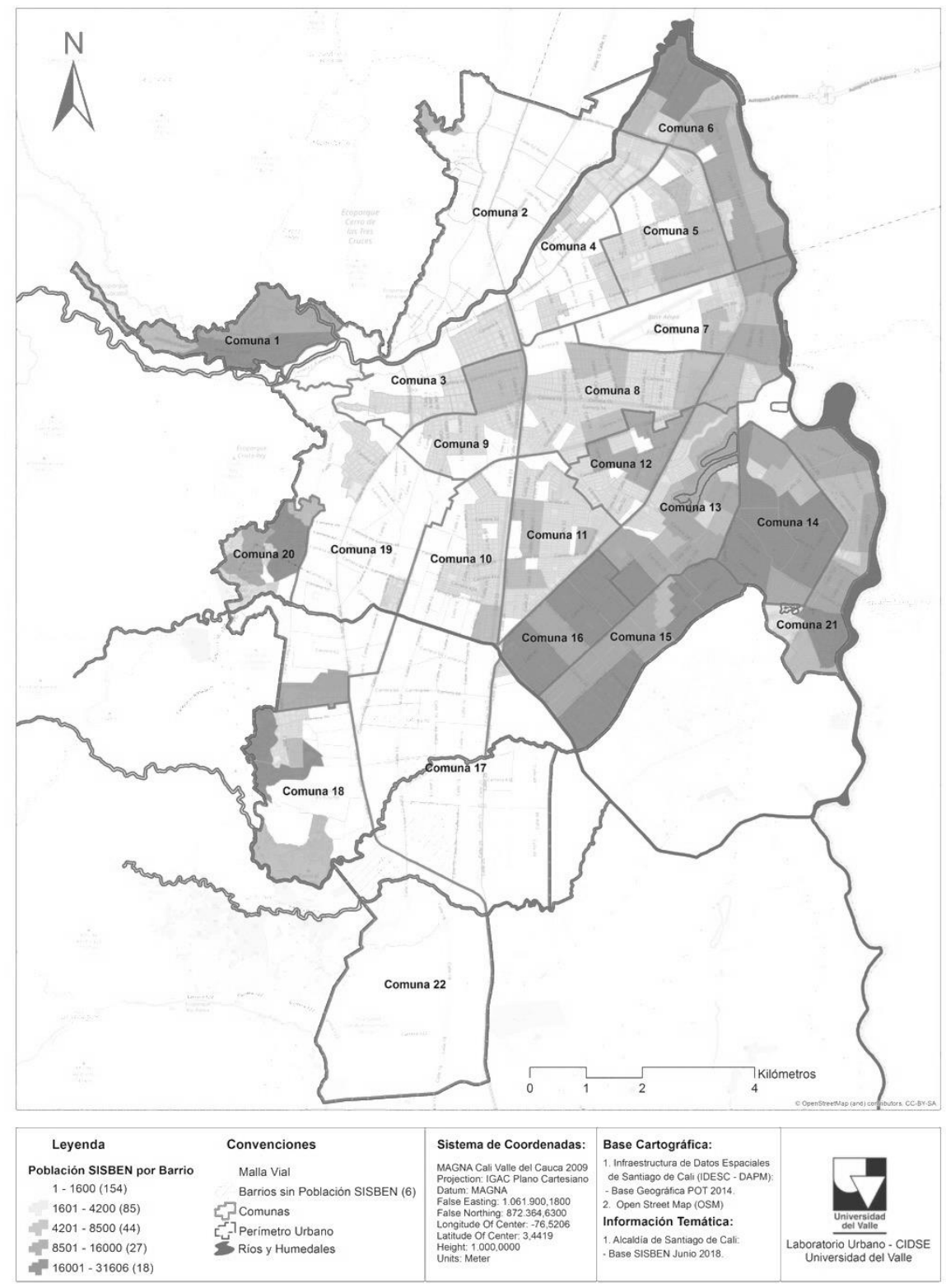

Fuente: elaboración propia con base de datos SISBEN (2019). 
Pero el análisis de las características socioeconómicas de la población SISBEN no se reducen al estrato socioeconómico, pues si bien en las comunas de alto estrato socioeconómico hay muy poca población registrada en el SISBEN, la poca población que se encuentra ahí, tiene un puntaje muy bajo. Es decir que existen nichos de pobreza en barrios y comunas de alto nivel de ingreso. La Tabla 1 muestra que, aunque en la comuna 22 hay un número muy bajo de personas identificadas por el SISBEN, solo el 0,05\% la población urbana, más el 30\% de la población registrada en esta comuna reporta un puntaje inferior a 40 puntos lo que constituye un indicador de la precariedad de sus condiciones de vida, en medio de la riqueza.

\section{Tabla 1}

Población SISBEN según rangos de puntaje desagregado por comuna ${ }^{7}$

\begin{tabular}{ccccccccccc}
\hline Comuna & $\mathbf{0 - 1 0}$ & $\mathbf{1 1 - 2 0}$ & $\mathbf{2 1 - 3 0}$ & $\mathbf{3 1 - 4 0}$ & $\mathbf{4 1 - 5 0}$ & $\mathbf{5 1 - 6 0}$ & $\mathbf{6 1 - 7 0}$ & $\mathbf{7 1 - 8 0}$ & $\mathbf{8 1 - 9 0}$ & Total \\
\hline $\mathbf{1}$ & 2,8 & 10,6 & 16,1 & 18,6 & 20 & 16,8 & 10,8 & 4,3 & 0,1 & $100 \%$ \\
$\mathbf{2}$ & 5,3 & 13,1 & 18,6 & 19,7 & 18,1 & 14 & 7,8 & 3,2 & 0,2 & $100 \%$ \\
$\mathbf{3}$ & 6,6 & 19,1 & 18,7 & 12,8 & 14,2 & 13,2 & 10,3 & 4,8 & 0,2 & $100 \%$ \\
$\mathbf{4}$ & 1,1 & 7,4 & 14 & 16,3 & 18,1 & 18,1 & 15,8 & 8,9 & 0,4 & $100 \%$ \\
$\mathbf{5}$ & 0,3 & 2 & 5 & 8,1 & 14 & 20,3 & 27,8 & 21,1 & 1,4 & $100 \%$ \\
$\mathbf{6}$ & 1,4 & 5,5 & 9,6 & 14,2 & 17,6 & 19,2 & 20,1 & 12 & 0,6 & $100 \%$ \\
$\mathbf{7}$ & 2,9 & 8,9 & 14 & 17,5 & 18,5 & 15,5 & 14,6 & 7,8 & 0,4 & $100 \%$ \\
$\mathbf{8}$ & 1,2 & 6,3 & 12,2 & 13,1 & 17 & 18,5 & 19,1 & 12 & 0,6 & $100 \%$ \\
$\mathbf{9}$ & 4,3 & 18,6 & 21,9 & 15,7 & 15,1 & 11,9 & 8,4 & 3,9 & 0,2 & $100 \%$ \\
$\mathbf{1 0}$ & 1,4 & 9 & 18,7 & 18 & 19 & 14 & 12,6 & 7 & 0,2 & $100 \%$ \\
$\mathbf{1 1}$ & 1,1 & 5,8 & 11,7 & 16,2 & 18,1 & 19 & 18 & 9,6 & 0,4 & $100 \%$ \\
$\mathbf{1 2}$ & 1,2 & 6,6 & 14,1 & 18,1 & 19,6 & 16,8 & 15,4 & 7,8 & 0,3 & $100 \%$ \\
$\mathbf{1 3}$ & 2,5 & 8,6 & 14,5 & 19,6 & 19,2 & 16,3 & 13,5 & 5,6 & 0,2 & $100 \%$ \\
$\mathbf{1 4}$ & 1,8 & 8 & 14,4 & 20,1 & 20,9 & 17,8 & 12,4 & 4,5 & 0,1 & $100 \%$ \\
$\mathbf{1 5}$ & 2,7 & 9,1 & 15,1 & 19,2 & 19,3 & 16,5 & 12,7 & 5,2 & 0,2 & $100 \%$ \\
$\mathbf{1 6}$ & 1,6 & 7,9 & 14,5 & 19,6 & 21,3 & 16,3 & 12,8 & 5,8 & 0,2 & $100 \%$ \\
$\mathbf{1 7}$ & 2,3 & 5,1 & 13,7 & 15,8 & 19,6 & 18 & 14,1 & 10,3 & 1 & $100 \%$ \\
$\mathbf{1 8}$ & 3,5 & 12 & 17 & 18,9 & 18,1 & 15,4 & 10,5 & 4,5 & 0,2 & $100 \%$ \\
$\mathbf{1 9}$ & 3 & 10,2 & 18,2 & 18 & 18,8 & 15,2 & 11,6 & 4,9 & 0,1 & $100 \%$ \\
$\mathbf{2 0}$ & 4,1 & 15 & 20,3 & 19,7 & 18,4 & 13,1 & 7,3 & 2 & 0 & $100 \%$ \\
$\mathbf{2 1}$ & 2 & 8,2 & 12,8 & 17,6 & 19 & 18,8 & 14,9 & 6,4 & 0,2 & $100 \%$ \\
$\mathbf{2 2}$ & 2,2 & 8 & 7,3 & 23,4 & 13,7 & 21,8 & 13,1 & 10,5 & 0 & $100 \%$ \\
Total & 2,2 & 8,7 & 14,3 & 17,7 & 18,8 & 16,9 & 14,2 & 6,9 & 0,3 & $100 \%$ \\
comunas & & & & & & & & & & \\
\hline & & & & & & & &
\end{tabular}

Fuente: elaboración propia con base de datos de SISBEN (2019).

\footnotetext{
${ }^{7}$ Como se explica en el texto, se resaltan los datos de la comuna 22 que es una comuna del alto estrato socio económico para hacer énfasis en que incluso en estas comunas existe población con bajos puntaje SISBEN, lo que indica que se encuentra en condición de pobreza y vulnerabilidad. Generalmente son empleadas de servicio internas o población que ha invadido pequeños lotes y se encuentra sisbenizada.
} 
De hecho, una de las modificaciones introducidas en el cálculo del puntaje en SISBEN fue la exclusión del estrato socioeconómico. El puntaje SISBEN se calcula a través de un mecanismo de componentes principales que pondera un conjunto de variables que posibilitan identificar el nivel de vulnerabilidad de la población encuestada. En SISBEN se prioriza el enfoque de capacidades sobre el utilitarista, asociado principalmente a características físicas, que en versiones anteriores eran capturadas en las variables de estrato socioeconómico, pues se asocia esta variable a condiciones de infraestructura de la población encuestada (Flores et al., 2008). Esta fue una de las razones por las que se excluyó la variable de estrato socioeconómico del cálculo del puntaje SISBEN y es lo que explica que en comunas de alto estrato socioeconómico se encuentre localizada población con bajo puntaje. En sintonía con esta perspectiva, la nueva encuesta SISBEN aplicada a partir de julio del 2019, profundiza en el enfoque de capacidades, con preguntas sobre la capacidad de generación de ingresos de los hogares y no en las características de la vivienda ni en su entorno socioeconómico.

Por otra parte, a pesar de la alta cobertura de SISBEN con respecto al total de la población de la ciudad de Cali, una de las principales dificultades de este sistema es la actualización de los datos de los encuestados ya registrados. Si bien, el Departamento de Planeación Nacional definió un mecanismo para la actualización de la población, la falta de controles y monitoreo en la actualización de los registros, ha dificultado este proceso. Para el año 2016 el DNP reportó que el 74\% de la población registrada en el SISBEN no actualizaba sus registros (DNP, 2016), y los pocos que lo hicieron, solo actualizaban los campos asociados a su dirección, teléfono y edad, pero no actualizaron los datos asociados a todas las preguntas de la encuesta y principalmente a su situación socioeconómica. Esta conducta responde a que tal vez las personas tienen temor a perder subsidios estatales si su condición socioeconómica cambia (Conexión Sur, 2019).

Para Cali el 78\% de la población registrada en las bases de datos del SISBEN con corte junio 2019 no han actualizado su información (1.041.004 personas). Esto imposibilita realizar un análisis de corte longitudinal, que permite analizar los cambios en las condiciones de la población a lo largo del tiempo. El no poder saber cómo las condiciones de vida de la población en el SISBEN cambian a través del tiempo, nos obliga a estudiar las condiciones de pobreza de la población registrada en el 2009 y el 2019, evaluando sus características al momento de responder la encuesta para estas dos ventanas de observación. 
El periodo 2009 contiene la población registrada desde el 1 de enero del año 2009 hasta el 31 de diciembre del mismo año. En total se registraron 365.643 personas, que representan el 27,3\% del total de la población SISBEN (Figura 3) ${ }^{8}$. El periodo 2019 contiene la población registrada desde el 1 de enero del 2016 hasta el 31 de junio del 2019, en el que se registraron 310.770 personas, que representan el 23,2\% del total de la población SISBEN.

\section{Figura 3}

Distribución de la población total registrada en el SISBEN en el periodo 2009 y 2019

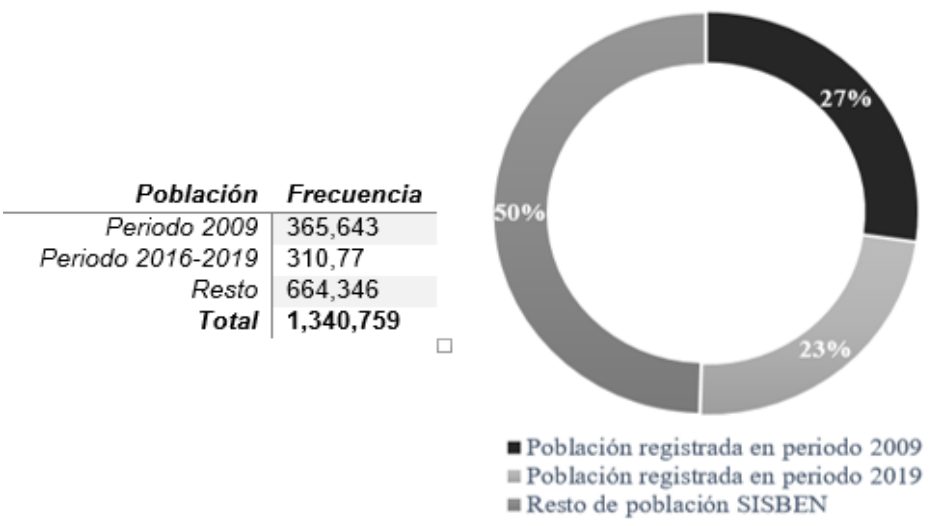

Fuente: elaboración propia con base de datos de SISBEN 2019.

La Figura 4 muestra las pirámides poblacionales por rangos quinquenales para ambos periodos. Este instrumento demográfico tiende a ser angosto en los rangos extremos de edad, en comparación al centro, en el caso de hombres y mujeres. Las longitudes de las cohortes inferiores (de 0 a 4 y de 5 a 9 años) muestran una menor participación de la población infantil, mientras que tiende a aumentar a medida que crece el rango de edad en las cohortes y, de nuevo, va disminuyendo a medida que crece la edad de las personas. El análisis de la distribución de la población SISBEN a través de esa pirámide muestra que la pobreza está afectando principalmente a la población joven (de 15 a 24 años) y adultos jóvenes (menor a los 40 años), por lo que tiende a tomar una forma piramidal restrictiva o regresiva. ¿Qué consecuencias trae esa situación? Que, si la población con bajo puntaje SISBEN está

\footnotetext{
${ }^{8}$ En el año 2009 ingresaron 547.861 individuos, sin embargo, para efectos del análisis únicamente se trabajará con quienes no hayan realizado modificación alguna desde la realización de la encuesta inicial, porque como ya se mencionó la actualización no se realiza sobre todas las variables de la encuesta.
} 
concentrada en ese rango de edad que corresponde a la edad productiva, entonces hay una baja probabilidad de salir de la pobreza.

\section{Figura 4}

Pirámides de la población registrada en periodo 2009 y 2019
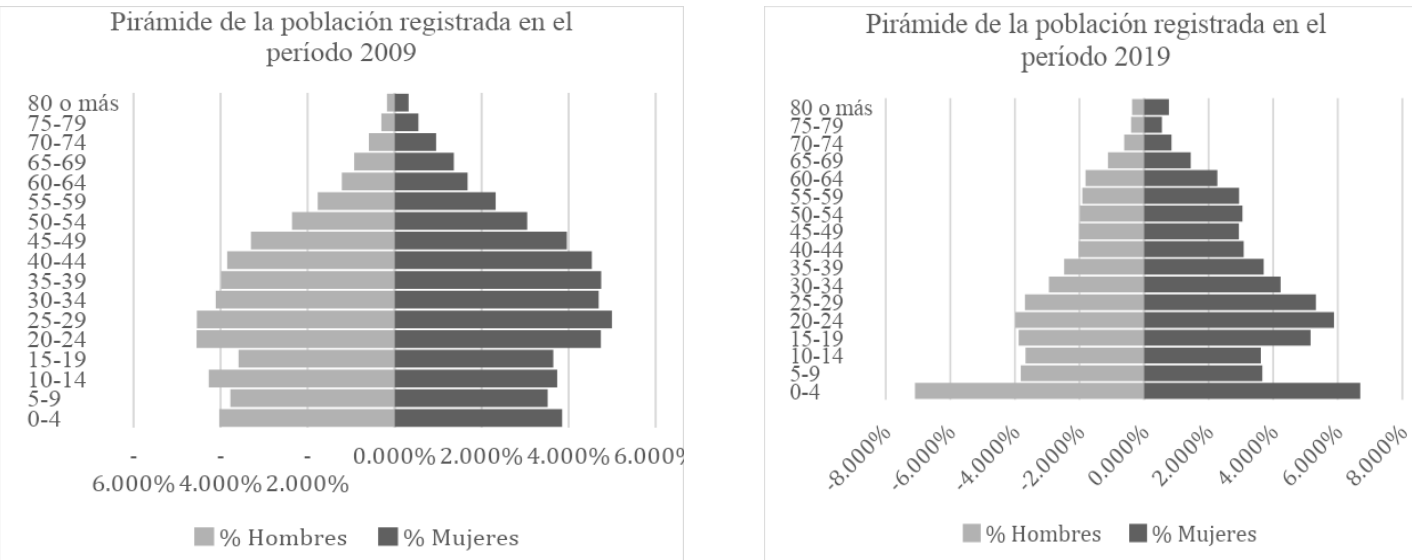

Fuente: elaboración propia con base de datos de SISBEN (2019).

Por otro lado, la población femenina es superior a la masculina en edades más avanzadas y menor en las cohortes inferiores. En el rango de 0 a 4 años la población masculina es superior a la femenina (23.729 mujeres y 25.184 hombres), razón que se repite hasta la cohorte de 15 a 19 años donde la situación se invierte, con más mujeres (55.880) que hombres (55.636).

Las pirámides de población nos muestran que, para ambos periodos, el porcentaje de mujeres es mayor que el de hombres. Estos datos del 2019 indican que la población mantiene las tendencias demográficas del Censo de población 1993 y 2005.

A nivel de comunas, la Figura 5 muestra que la población SISBEN se concentró, para el 2009, en el oriente (comuna 6, 13, 14, 15, 16, 21). Para el 2019, aunque el número de registros cayó, sigue estando concentrado en esas comunas. Para el caso de ladera, la comuna 1 registró un número menor, la 18 aumentó y la 20 casi que permaneció igual. 


\section{Figura 5}

Distribución de la población por comunas para el 2009 y 2019

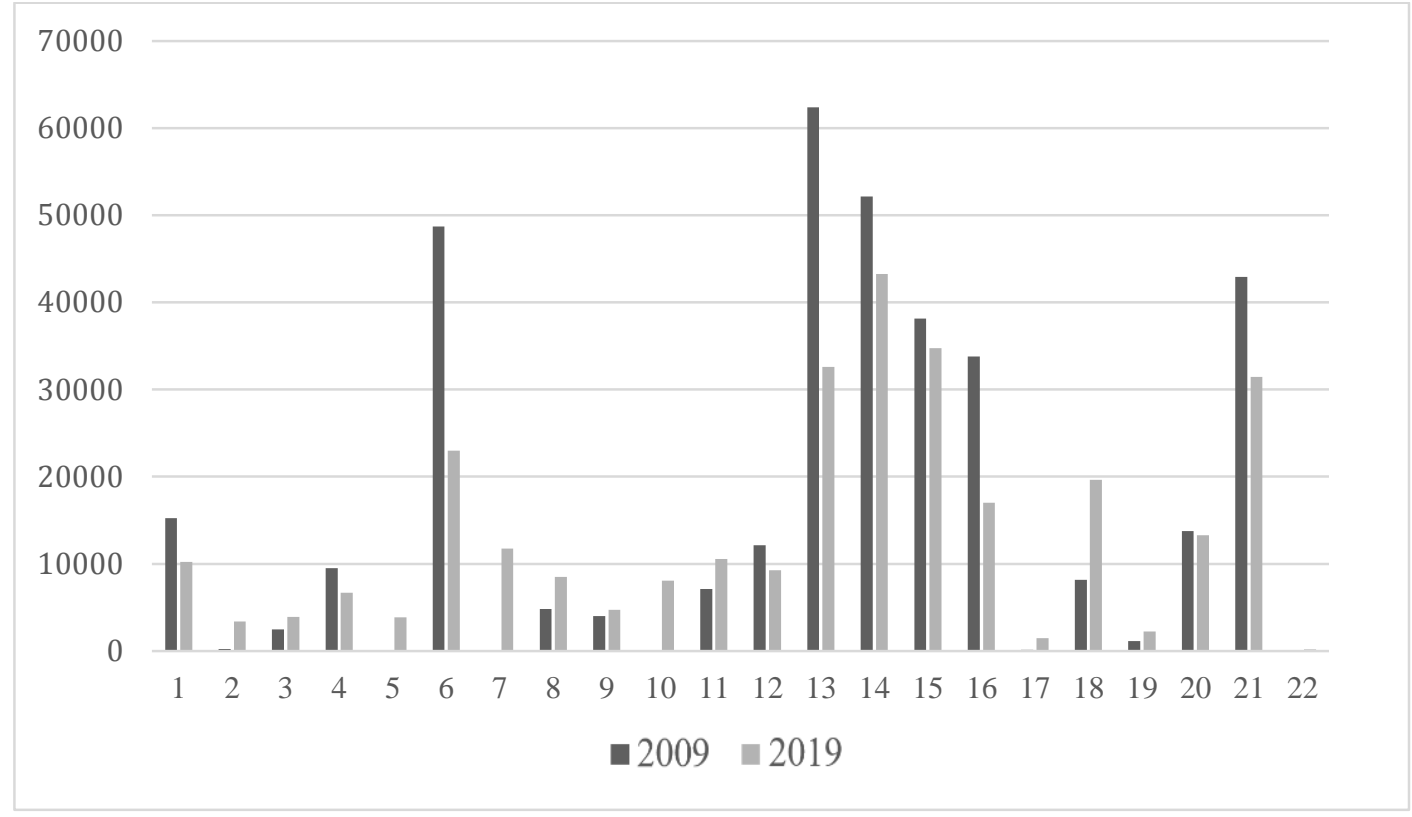

Fuente: elaboración propia con base de datos de SISBEN (2019).

Para las comunas 8 y 11 aparecen nuevos ingresos (superiores al 2009) que estarían indicando que en estas comunas con población en estratos 3 y 4, hubo mayor empobrecimiento, que se vio en la necesidad de recurrir al sistema como una forma de acceder a los subsidios del Estado.

\section{Metodología}

Para analizar las condiciones de pobreza y vulnerabilidad de los hogares registrados en el 2009 y 2019 , a nivel metodológico, se calculó, primero, el indicador de Necesidades Básicas Insatisfechas y la Línea de Pobreza Monetaria y, segundo, se clasificaron hogares de acuerdo a las tipologías propuestas bajo el enfoque de Kaztman (1989), definidas en la Figura 6. Esta clasificación permitió realizar un análisis comparativo del porcentaje de hogares en situación de pobreza crónica, de pobreza reciente, con carencias inerciales y en condición de integración social. 


\section{Figura 6}

Clasificación de los hogares de acuerdo a su nivel de ingreso y Necesidades Básicas Insatisfechas

\begin{tabular}{|c|c|c|}
\hline & $\begin{array}{l}\text { INGRESOS POR DEBAJO DE LA } \\
\text { LÍNEA DE POBREZA }\end{array}$ & $\begin{array}{l}\text { INGRESOS IGUALES O POR DEBAJO } \\
\text { DE LA LÍNEA DE POBREZA }\end{array}$ \\
\hline $\begin{array}{l}\text { HOGAR CATEGORIZADO COMO POBRE } \\
\text { SEGÚN NBI }\end{array}$ & $\begin{array}{l}\text { Hogares en situación de pobreza } \\
\text { crónica }\end{array}$ & Hogares con carencias inerciales \\
\hline $\begin{array}{l}\text { HOGAR CATEGORIZADO COMO NO } \\
\text { POBRE SEGÚN NBI }\end{array}$ & $\begin{array}{l}\text { Hogares en situación de pobreza } \\
\text { reciente }\end{array}$ & $\begin{array}{l}\text { Hogares en condición de integración } \\
\text { social }\end{array}$ \\
\hline \multicolumn{3}{|c|}{$\begin{array}{l}\text { Hogares en situación de pobreza crónica: Son los hogares que conforman el núcleo de la pobreza, y sus } \\
\text { características - incluyendo las subjetivas relacionadas al individuo, expectativas o apatía - propician su } \\
\text { reproducción o perpetuidad generacional. }\end{array}$} \\
\hline \multicolumn{3}{|c|}{$\begin{array}{l}\text { Hogares en situación de pobreza reciente: En estos hogares presentan inflexibilidad en condiciones de } \\
\text { vivienda frente a los cambios en la situación económica del hogar, y se adaptan rápidamente a los cambios } \\
\text { en los patrones de consumo vía niveles de ingresos. Cabe aclarar que los ingresos reportados en la encuesta } \\
\text { están sujetos a la actividad realizada por los miembros del hogar en el último mes. }\end{array}$} \\
\hline \multicolumn{3}{|c|}{$\begin{array}{l}\text { Hogares con carencias inerciales: Al estar ubicados por encima de la línea de pobreza monetaria, y esta, } \\
\text { al ser sólo un reflejo del momento de la encuesta, indica la existencia de una situación de pobreza mediante } \\
\text { intentos fallidos de mejorar las condiciones de vida del hogar }{ }^{9} \text {. Evidencia la existencia de dos posibles } \\
\text { escenarios, la falta de un mayor lapso de tiempo para solventar las privaciones en las diferentes dimensiones, }\end{array}$} \\
\hline \multicolumn{3}{|c|}{ Hogares en condición de integración social: Son hogares que poseen la mayoría de las condiciones } \\
\hline
\end{tabular}

Fuente: elaboración propia con base en Kaztman (1989, p. 146).

Para calcular el índice de NBI se utilizó la metodología propuesta por la CEPAL en Feres y Mancero (2001) que es la metodología oficial utilizada por el DANE (2019). Este índice considera dimensiones asociadas a las condiciones de vivienda de los hogares; la localización de las viviendas, si están o no ubicadas en asentamientos urbanos subnormales; el material de la vivienda, si tienen paredes o están hechas con material de desechos, entre otros. Se consideran la situación de hacinamiento de los hogares, es decir, si se encuentran en situación de hacinamiento crítico o moderado. El acceso a

\footnotetext{
${ }^{9}$ Para Kaztman (1989, p. 147) la presencia de carencias críticas en un hogar, puede ser el reflejo de una situación de pobreza anterior o el rezago de una condición de pobreza que de alguna manera estaría reflejando la historia social de los éxitos o fracasos de los hogares en los esfuerzos previos por acumular un patrimonio material que se refleje en mejores de vida de los hogares.
} 
servicios públicos básicos como el agua potable, eliminación de excretas. También la asistencia escolar, que se contabiliza como el número de niños entre 7 y 11 años de edad parientes del jefe de hogar que se encuentren fuera del sistema escolar. Finalmente, el índice considera la dependencia económica de los miembros del hogar, definida como la relación entre el número de personas que no reciben ingresos en relación con lo que reciben ingresos. Cuando un hogar presenta por lo menos una carencia básica, es considerado como un hogar con necesidades básicas insatisfechas y si presenta dos o más carencias es considerado en estado de miseria.

Ahora, para definir el número de hogares por debajo de la línea pobreza monetaria se utilizó la línea publicada por el DANE (2019) en su boletín técnico para el Valle del Cauca del año 2018, el cual establece que todas las personas con ingresos per-cápita por debajo de $\$ 259.561$ deben ser considerados como pobres. Adicionalmente, se deflactaron todos los ingresos reportados a precios constantes para el año 2018.

\section{Discusión de resultados}

\section{¿Cómo está la población sisbenizada?}

La tipología de hogar asociada a la condición de pobreza reciente es la que predomina para la población 2009 y 2019 (Figura 7). Estos hogares posiblemente experimentaron una reducción significativa de ingresos o de su consumo sin todavía estar en la condición de no poder suplir sus necesidades básicas. Es decir, que son hogares que cuentan con estándares sanitarios básicos, acceso a los servicios de educación y aseguramiento en salud, pero su nivel de ingresos se encuentra por debajo de la línea de pobreza monetaria, aumentando el riesgo de caer en la pobreza crónica. Esta pérdida de bienestar está directamente asociado a la pérdida de empleos formales o a la reducción de sus niveles de ingresos en las economías informales que les impide recuperar su capacidad adquisitiva. 


\section{Figura 7}

Distribución de la población SISBEN registrada en 2009 y 2019 por tipologías

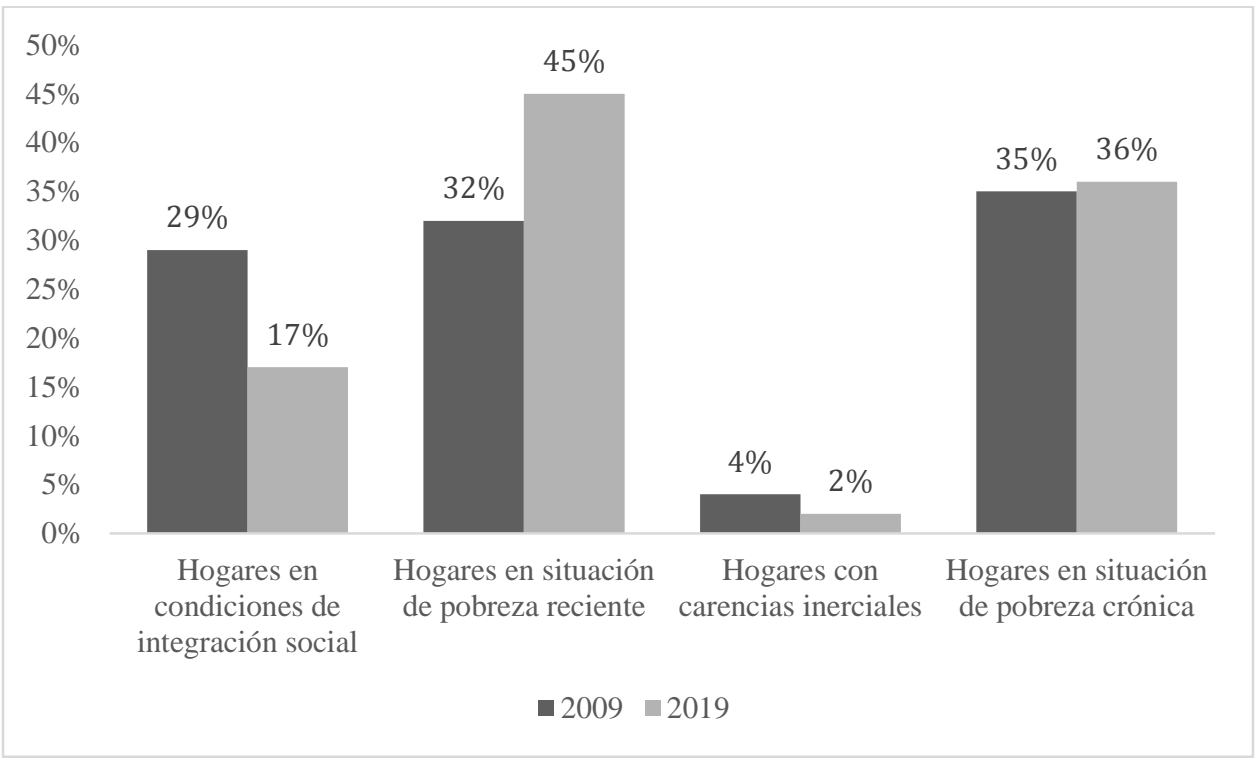

Fuente: elaboración propia con base en datos SISBEN (2019).

Frente a la categoría de hogares en condición de integración social, para el 2009 había un mayor porcentaje de hogares en esa situación, en comparación con la del 2019, es decir, la población que entró en este último periodo al sistema, está en peores condiciones en términos de su posesión o control de activos para aprovechar de la mejor manera las oportunidades que brinda el entorno en el que viven. Adicionalmente, en la población registrada en el período 2019 se encontró un mayor porcentaje de hogares en situación de pobreza crónica en relación con el 2009, indicando que esta población sigue reproduciendo y perpetuando su condición de pobreza. La información presentada en la Tabla 2 muestra que un porcentaje mayor de hogares recientemente identificados por el SISBEN en el período 2019 son más pobres en la categoría de crónicos y recientes, que los identificados en el año 2009.

\section{Tabla 2}

Distribución porcentual de acuerdo a la tipología de los hogares registrados en el SISBEN en Cali

\begin{tabular}{lcc}
\hline \multicolumn{1}{c}{ Tipologías de hogares } & 2009 & 2019 \\
\hline Hogares en condiciones de integración social & $29,2 \%$ & $16,7 \%$ \\
Hogares en situación de pobreza reciente & $32,4 \%$ & $45 \%$ \\
Hogares con carencias inerciales & $3,8 \%$ & $2,2 \%$ \\
Hogares en situación de pobreza crónica & $34,6 \%$ & $36 \%$ \\
Total & $100 \%$ & $100 \%$ \\
\hline
\end{tabular}

Fuente: elaboración propia con base en datos SISBEN (2019). 
A nivel de comunas la Figura 8 muestra la distribución de las tipologías de hogares para la ciudad. Aunque para las comunas 2 y 17 existen muy pocas personas registradas en el SISBEN (Figura 2), para el año 2009 la situación de pobreza crónica de estos hogares estaba asociada a que sus viviendas se encontraban localizadas en invasiones aledañas a barrios de alto estrato socioeconómico. En contraste, para el período 2019, la mayoría de población se encontraba en condición de pobreza reciente tanto en estas dos comunas como en el resto de comunas de la ciudad (Figura 8).

\section{Figura 8}

Distribución porcentual de las tipologías de hogares en Cali desagregado por comuna para el 2009 y 2019

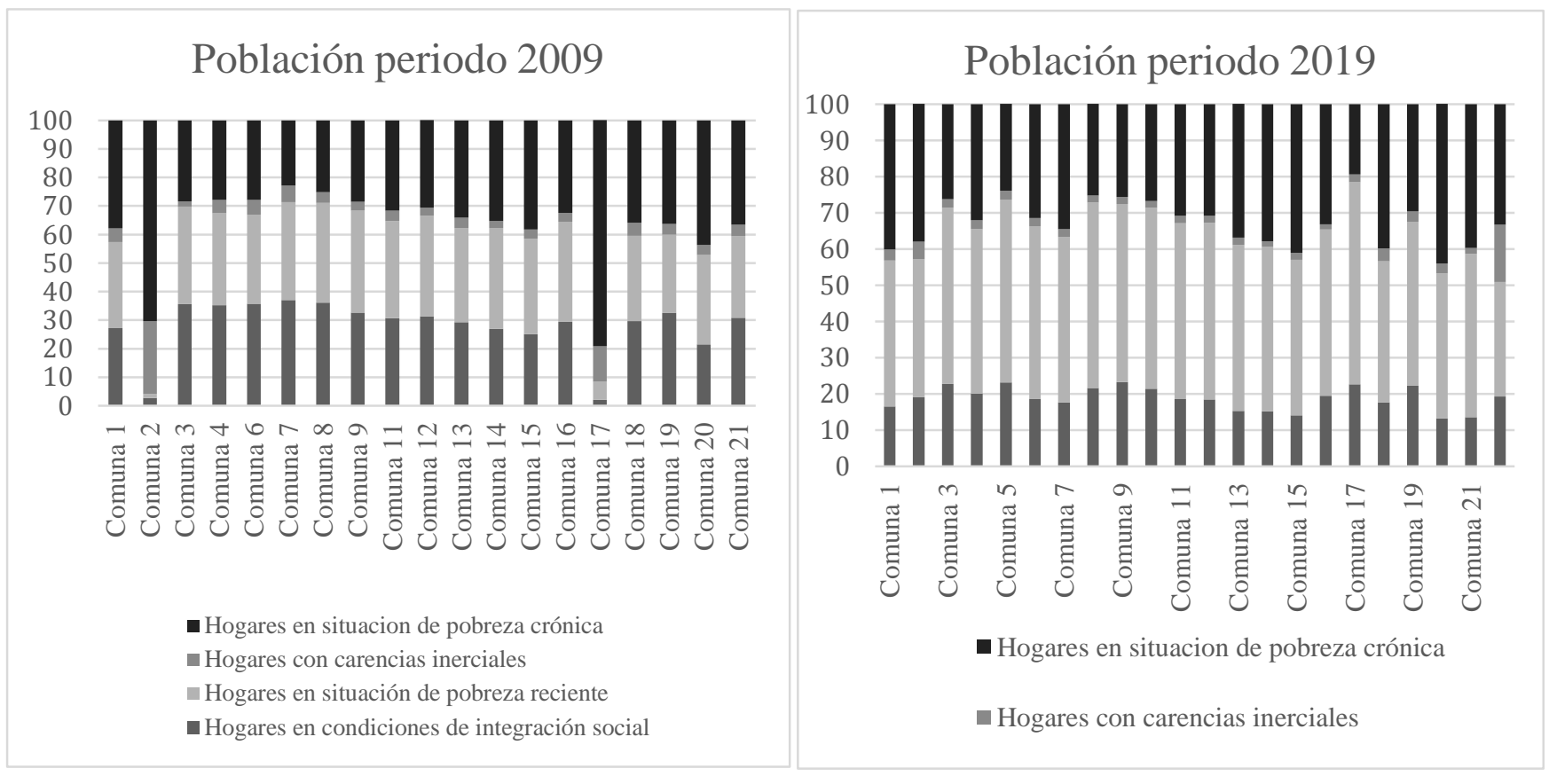

Fuente: elaboración propia con base en SISBEN (2019).

Aunque en Cali existe una enorme segregación residencial y los patrones de segregación agrupan a la población en clusters diferenciados de manera clara y con un alto nivel de aislamiento (Vivas, 2013), las tipologías de hogares, identificadas con base en la metodología de Kaztman (1989, 1997), se distribuyen de forma heterogénea en el área metropolitana de la ciudad donde se encuentra localizada la población sisbenizada. Este patrón se mantiene tanto en el año 2009 como en el 2019. La Figura 9 muestra los mapas con hogares georreferenciados de acuerdo a sus tipologías a nivel comuna y barrio. 
Estas dos imágenes indican que, aunque los pobres se siguen concentrando en las mismas zonas que históricamente han estado, con expansión a zonas aledañas, distintas formas de pobreza coexisten en un mismo espacio geográfico. Esto no excluye la posibilidad de que, en comunas muy específicas de la ciudad predomina cierto tipo de tipologías de pobreza, como por ejemplo en las comunas con asentamientos informales, donde, para los dos períodos, predominan las tipologías de hogar en situación de pobreza crónica. Por ejemplo, en los hogares localizados al borde de la Laguna de Charco Azul en la comuna 13 del Distrito de Aguablanca, al oriente de la ciudad, existe más homogeneidad, pues la mayoría de estos hogares se encuentran en situación de pobreza crónica, es decir, están en una mayor condición de vulnerabilidad, tanto por ingresos monetarios, como por los indicadores calculados para el Índice de Necesidades Básicas Insatisfechas.

\section{Figura 9}

Mapas de las tipologías de hogares para la población SISBEN registrada en 2009 y 2019
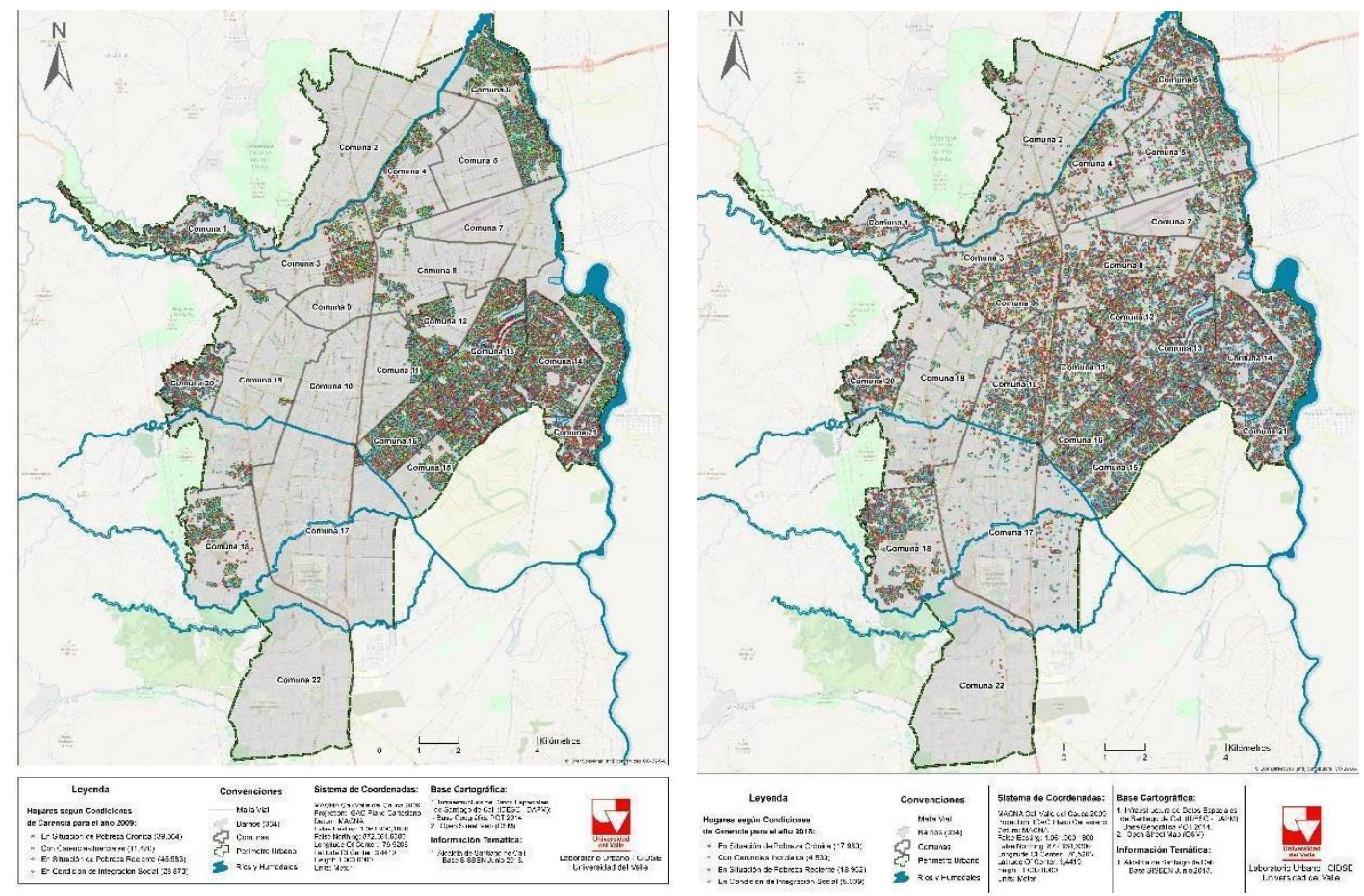

Fuente: elaboración propia con base en datos SISBEN (2019).

Mirando la expansión de la pobreza y vulnerabilidad en la ciudad de Cali, para el período 2009 la mayoría de la población sisbenizada se encontraba localizada en el oriente (comunas 13, 14, 15, 16 y 
21); en las laderas de la ciudad (comuna 1, 18 y 20); en la zona cercana al borde del Jarillón del río Cauca (comuna 6) y en los siguientes barrios más centrales de la ciudad: La Isla de la comuna 4, que fue un barrio de invasión en sus orígenes; San Nicolás en la comuna 3, que concentra un número importante de lugares comerciales; Sucre, considerado como "la olla" con mayores expendios de droga en Cali; y el barrio Obrero en la comuna 9. Mientras que, para el 2019, aparece población sisbenizada en comunas que antes no registraba ese tipo de población (Figura 8). En particular, aparecen hogares en situación de pobreza reciente y pobreza crónica en las comunas de alto-medio estrato socioeconómico y el número de hogares registrados en las comunas 5 y 10, que, aunque son las comunas que tienen la mayor proporción de hogares en condición de integración social. Esta es una población que se registró recientemente en el SISBEN, pues para el 2009 no había hogares de estas comunas registradas en este sistema de identificación, por tanto, tampoco se registraban hogares en condición de pobreza crónica o reciente.

A nivel barrio, el mayor número de hogares que se registraron durante el 2009 en el SISBEN estaban localizados en los barrios que se presentan en la Tabla 3. Los barrios con mayor concentración son Ciudadela Floralia de la comuna 6, Marianos Ramos y Antonio Nariño de la comuna 16, Mojica de la comuna 14, así como Terrón Colorado de la comuna 1.

\section{Tabla 3}

Distribución porcentual de las tipologías de pobreza en los barrios con mayor número de personas registradas en el SISBEN durante el período $2009^{10}$

\begin{tabular}{lrrrrr}
\hline & $\begin{array}{c}\text { Integración } \\
\text { social }\end{array}$ & $\begin{array}{c}\text { Pobreza } \\
\text { crónica }\end{array}$ & $\begin{array}{c}\text { Pobreza } \\
\text { inercial }\end{array}$ & $\begin{array}{c}\text { Pobreza } \\
\text { reciente }\end{array}$ & Total \\
\hline Ciudadela Floralia & 39 & 15,2 & 4,5 & 41,3 & 100 \\
Mariano Ramos & 28,9 & 22,3 & 3 & 45,9 & 100 \\
Antonio Nariño & 28,6 & 24,5 & 3 & 44 & 100 \\
Mojica & 21,1 & 30,4 & 2,5 & 46 & 100 \\
Terrón Colorado & 31,2 & 21,6 & 4,2 & 43 & 100 \\
Promociones Populares B & 24,4 & 25,8 & 2,9 & 46,9 & 100 \\
Alfonso Bonilla Aragón & 28,5 & 23,3 & 3,6 & 44,5 & 100 \\
Comuneros I & 20,7 & 33,3 & 2,5 & 43,5 & 100 \\
Valle Grande & 44,1 & 13,1 & 7,3 & 35,5 & 100 \\
\hline
\end{tabular}

${ }^{10}$ Los barrios que tienen el mayor número de personas registradas en el SISBEN durante el periodo 2009 son los que encabezan la lista. El orden de los barrios en la Tabla 4se encuentra asociado al número de personas que se registraron 


\begin{tabular}{lrrrrr}
\hline Unión de Vivienda Popular & 29,4 & 22,9 & 2,9 & 44,9 & 100 \\
El Vergel & 21,1 & 32,8 & 2,7 & 43,4 & 100 \\
José Manuel Marroquín I & 27,2 & 26,1 & 3 & 43,7 & 100 \\
José Manuel Marroquín II & 27 & 23,3 & 3,1 & 46,7 & 100 \\
República de Israel & 32 & 19,8 & 3,2 & 45,1 & 100 \\
Manuela Beltrán & 25 & 29,8 & 2,9 & 42,3 & 100 \\
El Morichal & 37,8 & 13,3 & 4,1 & 44,7 & 100 \\
El Poblado II & 27,8 & 25,1 & 2,7 & 44,3 & 100 \\
El Vallado & 32,6 & 18 & 3,6 & 45,8 & 100 \\
Calimio Desepaz & 34 & 17,8 & 4,1 & 44,1 & 100 \\
Siloé & 21,1 & 31,7 & 2,2 & 45 & 100 \\
Alirio Mora Beltrán & 27,6 & 24 & 3,2 & 45,2 & 100 \\
Potrero Grande & 11,3 & 42,4 & 1,3 & 45 & 100 \\
El Poblado I & 33,9 & 18,4 & 3,7 & 44 & 100 \\
El Rodeo & 30 & 23,4 & 3,2 & 43,4 & 100 \\
El Diamante & 31,4 & 19,1 & 3,3 & 46,2 & 100 \\
\hline
\end{tabular}

Fuente: elaboración propia con base en SISBEN (2019).

El barrio que concentró el mayor porcentaje de hogares en condición de pobreza crónica para la población registrada en el 2009 fue Potrero Grande, con un 42,4 \%. En este mismo barrio, el 45\% de los hogares se encontraban en condición de pobreza reciente, el 1,3\% en situación de carencias inerciales y el 11,3 \% en condición de integración social. Después de Potrero Grande, los barrios Comuneros I (33,3 \%), El Vergel (32,8 \%), Siloé (31,7 \%), Mojica (30,4 \%) y Manuela Beltrán (29,8 $\%$ ) concentran, en su orden, el mayor porcentaje de hogares en situación de pobreza crónica.

Por otra parte, como se observa en la Figura 9, la población registrada en el 2009 se encontraba localizada en 115 barrios y asentamientos urbanos subnormales principalmente en las zonas de oriente y ladera, mientras que la población del 2019 estaba localizada en 326 barrios o asentamientos informales de todas de las comunas de la ciudad. Las Tablas 3 y 4 solo muestran los barrios que reportan el mayor número de personas registradas en el SISBEN en los dos periodos de estudio. 


\section{Tabla 4}

Distribución porcentual de las tipologías de pobreza en los barrios con mayor número de personas registradas en el SISBEN en el 2019

\begin{tabular}{lrrrrr}
\hline \multicolumn{1}{c}{ Periodo 2019 } & $\begin{array}{r}\text { No } \\
\text { pobre }\end{array}$ & $\begin{array}{r}\text { Pobreza } \\
\text { crónica }\end{array}$ & $\begin{array}{r}\text { Pobreza } \\
\text { inercial }\end{array}$ & $\begin{array}{r}\text { Pobreza } \\
\text { reciente }\end{array}$ & $\begin{array}{r}\text { Total } \\
\text { \% fila }\end{array}$ \\
\hline El Morichal & 13,6 & 20,7 & 1,1 & 64,6 & 100 \\
Manuela Beltrán & 13 & 21,9 & 0,7 & 64,4 & 100 \\
Mojica & 13,5 & 22,8 & 1 & 62,8 & 100 \\
Ciudadela Floralia & 19,6 & 15,1 & 1 & 64,3 & 100 \\
Alfonso Bonilla Aragón & 16,6 & 20,1 & 1,2 & 62 & 100 \\
Promociones Populares B & 16,2 & 17,5 & 0,7 & 65,6 & 100 \\
José Manuel Marroquín I & 16,4 & 20,5 & 0,8 & 62,3 & 100 \\
Comuneros I & 12,4 & 28,7 & 1,1 & 57,7 & 100 \\
Potrero Grande & 8,6 & 21,1 & 0,3 & 70 & 100 \\
Mariano Ramos & 20,1 & 21,1 & 1 & 57,8 & 100 \\
El Vergel & 13,5 & 22,7 & 0,6 & 63,2 & 100 \\
José Manuel Marroquín II & 17,5 & 21,4 & 0,6 & 60,5 & 100 \\
Terrón Colorado & 20,1 & 19 & 1 & 59,9 & 100 \\
Antonio Nariño & 19 & 21,4 & 1,1 & 58,4 & 100 \\
Siloé & 15 & 29,9 & 0,9 & 54,2 & 100 \\
Unión de Vivienda Popular & 19,9 & 18,5 & 0,9 & 60,7 & 100 \\
Desepaz Invicali & 14,1 & 19,8 & 0,4 & 65,7 & 100 \\
Sector Alto de Los Chorros & 15 & 29,6 & 2,9 & 52,5 & 100 \\
Sector Alto Jordán & 19,3 & 23,5 & 2 & 55,2 & 100 \\
El Vallado & 20,3 & 18,1 & 1 & 60,7 & 100 \\
El Poblado II & 16,3 & 19,5 & 0,8 & 63,3 & 100 \\
Calimio Desepaz & 16,8 & 14,6 & 0,9 & 67,8 & 100 \\
Ciudad Cordoba & 20,2 & 13,7 & 0,7 & 65,4 & 100 \\
República de Israel & 21,2 & 17 & 0,8 & 61 & 100 \\
Las Orquídeas & 17 & 21 & 0,8 & 61,2 & 100 \\
Alirio Mora Beltrán & 17,9 & 17,7 & 0,7 & 63,6 & 100 \\
\hline
\end{tabular}

Fuente: elaboración propia con base en SISBEN (2019).

La mayoría de los hogares registrados en el 2019 (Tabla 4) se encuentran en condición de pobreza reciente. Durante este periodo, el barrio Morichal de la comuna 15 fue el barrio que concentró el mayor número de hogares. Para el 2009 este barrio tenía muy poca población registrada en el SISBEN pues su mayoría de los habitantes eran empleados formales, operarios de empresas con prestaciones sociales y seguridad social. Sin embargo, para el 2019 se incrementó el número de hogares registrados en este barrio y el mayor porcentaje de ellos se encuentran en condición de pobreza reciente, es decir que son hogares cuyo nivel de ingresos se redujo y se encuentra por debajo de la línea de pobreza 
monetaria, aunque no se encuentran en condición de necesidades básicas insatisfechas. Así mismo durante este último periodo se registró un número considerable de hogares del sector Altos de los Chorros y la mayoría de los hogares se encontraba en condición de pobreza reciente $(52,5 \%)$ y de carencias inerciales.

Durante ese mismo periodo también se registraron algunos hogares localizados en los asentamientos del Jarillón del Río Cauca I, II, III y la mayoría de estos hogares se encontraban en situación de pobreza crónica. Una situación análoga se identificó en los asentamientos de La Laguna del Pondaje con el $34,8 \%$, Villamercedes I (32,4 \%) y en Alto Nápoles $(30,3 \%)$.

\section{¿Cómo están los jóvenes sisbenizados en Cali?}

Ahora bien, categorizando por tipologías los hogares de la población juvenil, se identificó que su situación de pobreza, cuyo jefe de hogar entre los 14-28 años de edad, puede ser todavía más aguda. Esta población, en el 2019, se encuentra en peores condiciones que los que entraron al SISBEN en el periodo 2009. Un hecho preocupante que arrojan los datos es que el porcentaje de hogares en situación de pobreza crónica para la población juvenil es mayor para ambos periodos en comparación con la distribución de la tipología de hogares para el total de la población registrada en 2009 y 2019 (Tabla 5). Esto quiere decir que los hogares registrados en el SISBEN cuyo jefe de hogar se encuentra entre los 14 y 28 años son más vulnerables, pero no solamente ahora. Su condición de vulnerabilidad se ha ido prolongando en el tiempo, enfrentándose a un contexto estructural de oportunidades limitadas que imposibilita mejorar sus condiciones de vida en un futuro cercano.

\section{Tabla 5}

Distribución porcentual de los hogares cuyo jefe de hogar está entre los 14 y 28 años para el 2009 y 2019

\begin{tabular}{lcc}
\hline \multicolumn{1}{c}{ Tipologías de hogares } & 2009 & 2019 \\
\hline Hogares en condiciones de integración social & $26,30 \%$ & $13,10 \%$ \\
Hogares en situación de pobreza reciente & $30 \%$ & $38,40 \%$ \\
Hogares con carencias inerciales & $4,40 \%$ & $2,50 \%$ \\
Hogares en situación de pobreza crónica & $39,30 \%$ & $46 \%$ \\
Todo & $100 \%$ & $100 \%$ \\
\hline
\end{tabular}

Fuente: elaboración propia con base en datos SISBEN (2019). 
A pesar de las supuestas ventajas relativas de la población juvenil, los jóvenes de las zonas marginales, cargan con el peso de las condiciones de pobreza y segregación que heredaron de sus padres o abuelos. Pero, además, esta situación se agrava para las mujeres jóvenes pues además "existe una alta correlación entre la baja educación y la propensión a la maternidad adolescente. Las jóvenes pobres con escolaridad limitada tienden a caer en el embarazo adolescente. Entre otras cosas, sus insuficiencias educativas limitan los recursos para evitarlo y prevenirlo” (Sen y Kliksberg, 2007, p. 211), esto reproduce el ciclo de pobreza y marginalidad. De hecho, uno de los resultados más preocupantes del análisis de la población registrada en el SISBEN es que tanto para el 2009 como para el 2019 el mayor porcentaje de hogares en situación de pobreza crónica eran hogares cuyo jefe de hogar era una mujer joven entre 14 y 28 años.

Los datos reflejan que la situación de los jóvenes es más precaria en relación con otros grupos etarios. "La exclusión social, junto con la desarticulación familiar, coloca a un sector de la juventud de la región en una situación de jóvenes acorralados que pueden empujar su inserción en el mundo de los maras y del delito". (Sen y Kliksberg, 2007, p. 211).

En las Tablas 6 y 7 se muestra la proporción de mujeres que tienen un hijo o se encuentran en embarazo, de acuerdo a su rango de edad. Estos datos indican que las mujeres entre 12 y 19 años con esas características, pertenecen mayoritariamente a hogares en condición de pobreza crónica.

Kaztman (1997) explica este efecto como resultado de un ambiente hostil en que viven dichos jóvenes, experimentando un aislamiento social y laboral, que genera una serie de carencias asociada a los efectos de un embarazo adolescente. Pues, el periodo durante el cual una pareja posterga la concepción del primer hijo es un lapso de tiempo que pueden dedicar a la inversión en capital humano y fijo. Por tanto, ese periodo es fundamental para lograr un mayor bienestar ya que, entre más se postergue la maternidad la pareja o especialmente la madre, contará con más tiempo para poder acumular y desarrollar sus capitales. El caso de embarazo adolescente es el extremo negativo, debido a que la etapa previa de inversión es casi nula, las responsabilidades de la maternidad son rivales con cualquier otra actividad por la cantidad de tiempo que absorbe los cuidados de un niño. Todo esto permite concluir que el capital humano que pueda adquirir una mujer está relacionado positivamente por el periodo de tiempo en que se postergue su maternidad. 


\section{Tabla 6}

Mujeres con hijos o en embarazo desagregado por tipología de pobreza registradas en el SISBEN para el 2009

\begin{tabular}{|c|c|c|c|c|c|c|c|c|c|c|c|c|c|c|c|}
\hline \multirow[t]{2}{*}{ Edad } & \multirow[t]{2}{*}{ Total } & \multirow[t]{2}{*}{$\% c$} & \multirow[t]{2}{*}{$\% \mathrm{f}$} & \multicolumn{3}{|c|}{$\begin{array}{l}\text { Integración } \\
\text { social }\end{array}$} & \multicolumn{3}{|c|}{ Pobreza crónica } & \multicolumn{3}{|c|}{$\begin{array}{l}\text { Pobreza } \\
\text { inercial }\end{array}$} & \multicolumn{3}{|c|}{$\begin{array}{l}\text { Pobreza } \\
\text { reciente }\end{array}$} \\
\hline & & & & $\mathrm{N}$ & $\% c$ & $\% \mathrm{f}$ & $\mathrm{N}$ & $\% c$ & $7 f$ & $\mathrm{~N}$ & $\% c$ & $\% \mathrm{f}$ & $\mathrm{N}$ & $\% \mathrm{c}$ & $\% \mathrm{f}$ \\
\hline otal & & 100 & 0 & 172 & & 6,1 & & & & 179 & 100 & , & Jor & 100 & 20 , \\
\hline 13 & & & & 2 & & 14 & & & & & & & & 2 & 5 \\
\hline 1 & 3 & 1 , & 10 & 3 & 1, & 7, & & 1 & & 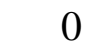 & 0 & & 15 & 6 & 39,5 \\
\hline 1 & 8 & 2 & & 7 & 4, & 8, & & 1 & & 1 & 0,6 & & 5 & 6 & 18,5 \\
\hline 16 & & & & 7 & 4,1 & 4,6 & 9 & & & 7 & 3,9 & 4,6 & 0 & 1 & 26,5 \\
\hline 17 & &, 7 & & 19 & 11 & 6,9 & 7 &, 8 &, 9 & 34 & 19 & 12,4 & 54 & 9,5 & 19,7 \\
\hline 18 & & 33,6 & 100 & 57 & 33,1 & 6 & 642 & 33,8 & 6 & 53 & 29,6 & 5,6 & 195 & 34,4 & 20,6 \\
\hline 14 & 314 & 46,6 & 100 & 77 & 44,8 & 5,9 & 912 & 48 & 69,4 & 84 & 46,9 & 6,4 & 241 & 42,5 & 18,3 \\
\hline
\end{tabular}

Fuente: elaboración propia con base en la base de datos SISBEN (2019).

\section{Tabla 7}

Mujeres con hijos o en embarazo desagregado por tipología de pobreza registradas en el SISBEN para el 2019

\begin{tabular}{|c|c|c|c|c|c|c|c|c|c|c|c|c|c|c|c|}
\hline \multirow{2}{*}{ Edad } & \multirow{2}{*}{ Total } & \multirow{2}{*}{$\% \mathrm{c}$} & \multirow[b]{2}{*}{$\% \mathrm{t}$} & \multicolumn{3}{|c|}{ No pobre } & \multicolumn{3}{|c|}{ Pobreza crónica } & \multicolumn{3}{|c|}{ Pobreza inercial } & \multicolumn{3}{|c|}{ Pobreza reciente } \\
\hline & & & & $\mathrm{N}$ & $\% \mathrm{c}$ & $\% \mathrm{f}$ & $\mathrm{N}$ & $\% \mathrm{c}$ & $\% \mathrm{f}$ & $\mathrm{N}$ & $\% \mathrm{c}$ & $\% \mathrm{f}$ & $\mathrm{N}$ & $\% \mathrm{c}$ & $\% \mathrm{f}$ \\
\hline tal & & 100 & 100 & 342 & 100 & 6, & 95 & 100 & 34,3 & 56 & 0 & 1,1 & 2843 & 100 & 57, \\
\hline 12 & & & & 0 & 0 & & 3 & & & & ,8 & 25 & & & \\
\hline 13 & 32 & 0 & & 4 & 1,2 & 12,5 & 14 & 0,8 & 43 & & 1,8 & 3,1 & 13 & 0,5 & 40,6 \\
\hline 14 & & & & 6 & 18 & & & & & & 0 & 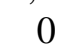 & 38 & 3 & 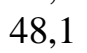 \\
\hline 15 & & 4, & & 13 & 3,8 & 5, & 87 & 5,1 & 39.4 & 2 & 3,6 & 0,9 & 119 & 2 & 53,8 \\
\hline 16 & & & & 1 & 5 & & & & & 0 & 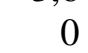 & & 240 & 4 & 57 \\
\hline 17 & & & & 45 & 13 & & & & & 6 &, 7 & 0,8 & 413 & 14,5 & 55 \\
\hline 18 & 15 & & & 93 & 27,2 & 5,9 & & & & 11 & 19,6 & 0,7 & 935 & 32,9 & 59,7 \\
\hline 19 & 18 & & 10 & 162 & 47,4 & 8.6 & 592 & 34,9 & 31,6 & 35 & 62,5 & 1,9 & 1085 & 38,2 & 57 \\
\hline
\end{tabular}

Fuente: elaboración propia con base en la base de datos SISBEN (2019). 


\section{Conclusiones}

La imagen de precariedad de la gente que vive en ladera y oriente en Cali recuerdan que Cali sigue siendo una ciudad con una pobreza difícil de esconder y que las condiciones en que viven sus habitantes solo pueden ser superadas con políticas públicas focalizadas en esa población. Si bien, las comunas ubicadas en esas zonas de la ciudad siguen siendo las más pobres y con menor calidad de vida frente al resto de la ciudad, existen formas heterogéneas de pobreza en los mismos territorios y en diferentes comunas de la ciudad. Es como si la pobreza estuviese extendiéndose a otros lugares en los que solo había familias de ingresos altos.

Este trabajo pretendió establecer diferencias en las condiciones sociodemográficas de una población que entró al sistema SISBEN en el 2009 en comparación con la que ingresó en el 2019, aunque somos conscientes que son poblaciones distintas, el Sistema sí permite ver en términos de ciertos indicadores de pobreza usando la metodología de Kaztman $(1989,1997)$, si tales condiciones han mejorado o empeorado para la ciudad de Cali, acercándonos a un diagnóstico de la pobreza a nivel de comunas y barrios.

Un primer hallazgo que reportan el análisis de los datos de SISBEN es que los hogares que ingresaron en el 2019 se encuentran en peores condiciones, que los registrados en el 2009. Los datos de la población identificada en el período 2019 reportaron un mayor porcentaje de hogares en condición de pobreza monetaria, pobreza extrema y pobreza multidimensional.

Un segundo hallazgo indica que, aunque la población en condición de pobreza se encuentra localizada fundamentalmente en las zonas de oriente y ladera, coexisten formas heterogéneas de pobreza y de falta de oportunidades en un mismo territorio. Los datos muestran que, con excepción de algunas zonas muy específicas como en los asentamientos informales, en Cali, se encuentran, de manera adyacente, hogares con distintas tipologías de pobreza. Un tercer resultado, aún más preocupante, es la situación de la población joven de la ciudad, la falta de oportunidades laborales hace que sea ese el grupo etario con mayor incidencia de pobreza.

Las políticas de gobierno deben focalizarse en la población en situación de pobreza crónica y carencias inerciales. Estas políticas podrían estar asociadas a transferencias monetarias directas para 
el mejoramiento de vivienda o créditos sin tasa de interés con el mismo fin para que la población vulnerable pueda superar su condición de necesidades básicas insatisfechas. Esto sin perder de vista que la población en situación de pobreza crónica no solo necesita mejorar las condiciones de su vivienda, sino que también requiere un ingreso mínimo de subsistencia. De igual forma, es importante tener en cuenta que la población en situación de pobreza reciente requiere un apoyo especial para incrementar tu nivel de ingresos y superar su condición de pobreza monetaria. Estrategias que podrían estar asociadas a transferencias monetarias directas mayores por parte del gobierno nacional como ocurre con el programa Jóvenes en Acción, Familias en Acción, o con el programa Adulto Mayor, pero esto resolvería parcialmente el nivel de ingresos monetarios de los hogares en una situación de vulnerabilidad. Una política orientada a la de generación de ingresos para la población, sobre todo joven, a través de los canales de búsqueda de empleo o de desarrollo de sus actividades productivas, podría ser más efectiva en el mediano y largo plazo sin los costos fiscales que implican las transferencias monetarias directas sin contrapartida. La segunda opción le daría la posibilidad a la población de generar ingresos vía su trabajo.

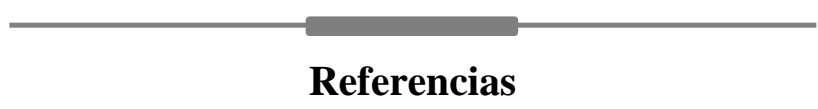

(1) Alkire, S. \& Foster, J. (2009). Counting and Multidimensional Poverty Measurement (revised and updated). OPHI Working Paper 32, University of Oxford.

(2) Angulo, R., Díaz, Y. y Pardo, R. (2011). Índice de pobreza multidimensional para Colombia (IPM-Colombia) 1997-2010. Archivos de Economía, (382).

(3) Castañeda, T. (2005). Targeting social spending to the poor with proxy means testing: Colombia's SISBEN system. World bank human Development Network social protection unit discussion paper, (529).

(4) Comisión Económica para América Latina y el Caribe [CEPAL] y Organización Iberoamericana de la Juventud. (2004). La juventud en Iberoamérica: tendencias y urgencias.

(5) Concejo Santiago de Cali. (2018, 2 de abril). Indicadores de encuesta Sisben deja por fuera del subsidio de salud a más de 98 mil caleños, Concejales cuestionan medición. http://www.concejodecali.gov.co/Publicaciones/indicadores_de_encuesta_sisben_deja_por_fuer a_del_subsidio_de_salud_a_mas_de_98_mil_calenos_concejales_cuestionan_medicion\#: :text 
$=$ Concejales $\% 20$ cuestionan $\% 20$ medici $\% \mathrm{C} 3 \% \mathrm{~B} 3 \mathrm{n}-$

,Indicadores $\% 20 \mathrm{de} \% 20$ encuesta $\% 20$ Sisben $\% 20 \mathrm{deja} \% 20$ por $\% 20$ fuera $\% 20 \mathrm{del} \% 20$ subsidio\%20d e,Cali\%2C\%20abril\%202\%20de\%202018.\&text=A\%20la\%20fecha\%2C\%2098.616\%20person as,por\%20fuera\%20de\%20ese\%20servicio.

(6) Conexión Sur. (2019, 9 de octubre). Comunidad del área rural de Andes reacia a encuesta del SISBEN [Publicación]. Facebook. https://www.facebook.com/ConexionSur1/posts/951920221852715/

(7) Correa, M. V. (2017, noviembre 22). 40,5 millones de colombianos estarán en 2019 en el Sisbén. El Colombiano. Tomado de https://www.elcolombiano.com/colombia/40-5-millones-de colombianos-estaran-en-2019-en-el-SISBEN-IA7741749

(8) Departamento Administrativo Nacional de Estadística [DANE]. (2019). Pobreza monetaria en Colombia aก̃o 2018. https://www.dane.gov.co/files/investigaciones/condiciones_vida/pobreza/2018/bt_pobreza_mon etaria_18.pdf

(9) Departamento Administrativo Nacional de Estadística [DANE] y Departamento Nacional de Planeación [DNP]. (2012). Misión para el empalme de las series de empleo, pobreza y desigualdad (MESEP).

(10) Departamento Nacional de Planeación [DNP]. (2012). Documento Conpes Social 150 Metodologías oficiales y arreglos institucionales para la medición de la pobreza en Colombia. https://colaboracion.dnp.gov.co/CDT/Conpes/Social/150.pdf

(11) Departamento Nacional de Planeación [DNP]. (2016). Documento CONPES 3877 Declaración de importancia estratégica del sistema de identificación de potenciales beneficiarios (SISBEN IV).

(12) Feres, J. C., y Mancero, X. (2001). Enfoques para la medición de la pobreza. Breve revisión de la literatura. Cuaderno $\mathrm{N}^{\circ} 4$ de la Serie Estudios Estadísticos y Proyecciones.

(13)Flores, C. E., Espinosa, F., Sánchez, L. M., y Angulo, R. (2008). Diseño del Índice Sisben en su tercera versión: SISBEN III. Departamento Nacional de Planeación-DNP.

(14) Herrera, J. (2010, del 28 al 29 de julio). Medición de la pobreza monetaria: desarrollos recientes [Presentación]. Seminario Internacional Colombia en las Nuevas Tendencias de Medición de la Pobreza y la Igualdad de Oportunidades. Bogotá, D. C., Colombia. 
(15) Kaztman, R. (1989). La heterogeneidad de la pobreza. El caso de Montevideo. Revista de la CEPAL, (37), 141-152.

(16) Kaztman, R. (1997). Marginalidad e integración social en Uruguay. Revista de la CEPAL, (62), 91-116.

(17)Ley 715 de 2001. (2001, 21 de diciembre). Congreso de la República de Colombia. Diario oficial No 44.654. http://www.suin-juriscol.gov.co/viewDocument.asp?ruta=Leyes/1666964

(18)López, J. (2020). Experimentando con la pobreza: El SISBEN y los proyectos de analítica de datos en Colombia. https://doi.org/10.13140/RG.2.2.19489.15207

(19) Merrick, T. W. (1997). La población de América Latina 1930-1990 (Economía y sociedad desde 1930 ed., Vol. 11). (L. Bethell, \& Crítica, 2000, Edits.). Historia de América Latina.

(20) Mier y Terán, A., Vázquez, I., y A. Ziccardi. (2012). Pobreza urbana, segregación residencial y mejoramiento del espacio público en la Ciudad de México. Sociologias, 14(30), 118155. https://doi.org/10.1590/S1517-45222012000200005

(21) Mosquera, G. y Aprile-Gniset, J. (1984). Clases, segregación y barrios. Universidad del Valle.

(22) Sarmiento, A., González, J. I. y Rodríguez, L. A. (1999). Eficiencia horizontal y eficiencia vertical del Sistema de Selección de Beneficiarios (SISBEN). Coyuntura Social, 107-125. http://hdl.handle.net/11445/1777

(23) Sassen, S. (2015). Expulsiones: brutalidad y complejidad en la economía global. Katz editores.

(24) Schubert, B. (1995). Poverty and poverty alleviation programmes in the urban areas of Mozambique. Habitat International, 19(4), 499-514. https://doi.org/10.1016/01973975(95)00042-E

(25) Sen, A. (1979). Issues in the measurement of poverty. Scandinavian Journal of Economics, (81), 285-307.

(26) Sen, A. (1983). Poor, relatively speaking. Oxford Economic Papers, 35(2), 153-169.

(27) Sen, A. (1984). The living standard. Oxford Economic Papers, 36, 74-90. https://doi.org/10.1093/oxfordjournals.oep.a041662

(28) Sen, A. (1985). A sociological approach to the measurement of poverty: A reply to Professor Peter Townsend. Oxford Economic Papers, 37(4), 669-676.

(29) Sen, A. (1987). Commodities and capabilities. Oxford India Paperbacks.

(30) Sen, A., y Kliksberg, B. (2007). Primero la gente: una mirada desde la ética del desarrollo a los principales problemas del mundo globalizado (No. 330.13/S47p). 
(31)SISBEN. (2019). Base de Datos del Sistema de Identificación de Potenciales Beneficiarios de Servicios Sociales, corte a Junio de 2019 - Cali. Universidad del Valle [Data set]. No disponibles para el público.

(32) Spicker, P. (2009). Definiciones de Pobreza: Doce grupos de significados. Pobreza: Un glosario internacional, 291-306. http://biblioteca.clacso.edu.ar/ar/libros/clacso/crop/glosario/06spicker.pdf

(33) Urrea, F. (1997). Dinámica sociodemográfica, mercado laboral y pobreza urbana en Cali durante las décadas de los años 80 y 90. Coyuntura Social, 105-164. http://hdl.handle.net/11445/1804

(34) Vásquez, E. y Arroyo, J. (2008). Factores ocultos del desarrollo del Valle del Cauca. Observatorio Económico y Social del Valle del Cauca, (8), 11-39.

(35) Vélez, C. E., Castaño, E. y Deutsch, R. (1999). Una interpretación económica del Sistema de Focalización de Programas Sociales: el caso SISBEN en Colombia. Coyuntura Social, 127-158. http://hdl.handle.net/11445/1778

(36) Vivas, H. (2013). Persistencia de la segregación residencial y composición del capital humano por barrios en la ciudad de Cali. Ensayos sobre Política Económica, 31(70), 121-155.

Cómo citar este artículo: Caicedo-Hurtado, M. y Castillo-Valencia, M. (2021). Tipologías de pobreza en Cali: un análisis con base en el SISBEN. Tendencias, 22(1), 39-70. https://doi.org/10.22267/rtend.202102.154 